Alma Mater Studiorum - Università di Bologna DEPARTMENT OF ECONOMICS

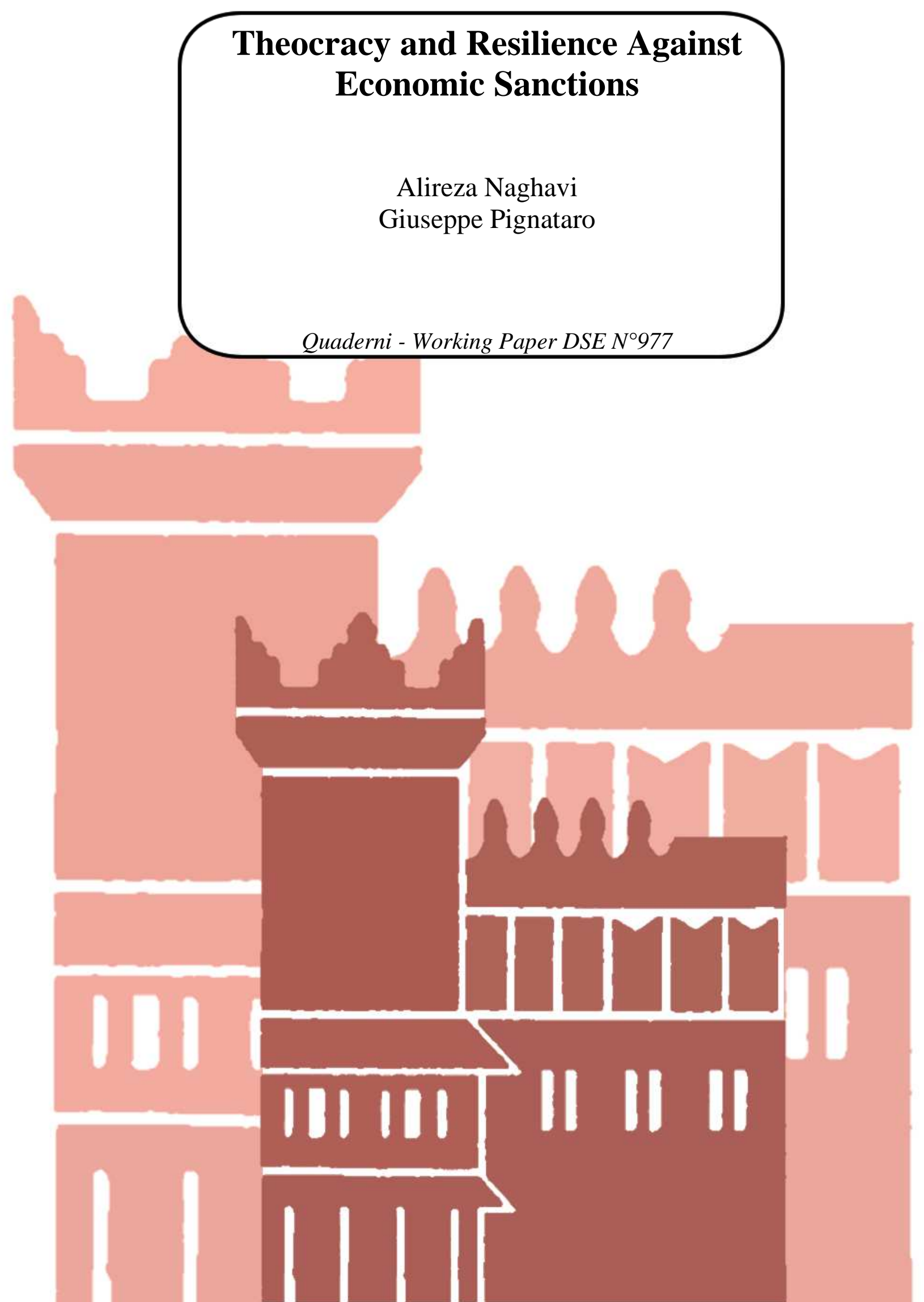




\title{
Theocracy and Resilience Against Economic Sanctions*
}

\author{
Alireza Naghavi $\dagger$ Giuseppe Pignataro ${ }^{\ddagger}$
}

December 2014

\begin{abstract}
This paper provides a simply theory to explain the impact of sanctions on a regime's policies and behavior. Sanctions are generally put to strip the target country from its available rents and weaken the government's stance against growing discontent in the population. We show however that sanctions may give legitimacy to an incumbent government by influencing the optimal level of religious ideology provided by the state and further stabilizing its grip to power and rents. While in a good state of nature sanctions build resilience as long as religious ideology among the population is strong, at bad times they compel the target country to move towards ideological moderation. In a world of asymmetric information, the target country always finds it optimal to send a signal that truly represents the prevailing state of nature in order to induce learning and reach a win-win outcome.

Keywords: Religion, Sanctions, Theocracy, Resilience, Bayesian learning. JEL classification Numbers: H10, Z12, P48, D74, D83.
\end{abstract}

\footnotetext{
*We are grateful to two anonymous referees for guiding us with valuable comments that substantially helped in improving the paper. We would also like to thank Mohammad Reza Farzanegan, Evelyn Korn, Florian Schuett, and the participants at the international symposium on "Sanctions and the Iranian Political Economy: Lessons and the Ways Forward" for valuable discussion and comments.

${ }^{\dagger}$ University of Bologna. Department of Economics, Piazza Scaravilli 2, 40126 Bologna, Italy, E-mail: alireza.naghavi@unibo.it

‡University of Bologna.
} giuseppe.pignataro@unibo.it. 


\section{Introduction}

Economic sanctions are becoming a routine policy instrument in international politics these days and tend to show up on the news on daily basis in an international scale. Sanctions often take place against extremist policies by target states. This could for example involve the violation of human rights, development of nuclear weapons, invasion of a recognized state, the use of expropriation and violence to retain power, or ideological extremism. As some examples of the latter Wintrobe (2006) mentions communism (control over the means of production), nationalism (control over territory) and religious fundamentalism (ridding the nation of foreign and secular influences). Extremist behavior can generally be associated with authoritarian regimes, against which sanctions have not have an impressive record in achieving their outcome. Empirical studies have linked this to the lack of prospects of reelection and therefore motivation by autocrats to please domestic constituencies (Nooruddin, 2002), lower destabilizing force of sanctions due to the low risk of removal faced by autocrats (Marinov, 2005), and less likelihood of political violence and protests occurring as a cause of sanctions in autocracies (Allen, 2008). But can ideology be used by the ruling regime in the target country to defy sanctions? When is the appropriate moment to impose a sanction or to remove an existing one?

This research provides a theory to explain the impact of sanctions on a regime's policies and behavior. It introduces a simple model to explain how an ideology such as religious beliefs can be employed in the target country as a tool of resilience to adapt to the new realities. Our model is inspired by a recent line of literature, namely Carvalho (2013), Cosgel and Miceli (2013) and Johnson and Koyama (2013), who study different aspects of enforcement of religious laws by the state. We show that inflicting religious laws or bestowing religious goods and services allows a theocracy to adjust to the economic hardship caused by sanctions and provides the option of ignoring sanctions. This is only possible when a sufficiently large fraction of the population derives utility from religion or if religious beliefs in that segment of the society are sufficiently strong. The state finds an optimal level of religious ideology to provide to the society in order to establish a new equilibrium. In principle, sanctions are put to strip the country from its available resource rents giving more weight to taxes as a secondary government source of income. As in Cosgel and Miceli (2009), the state obtains more legitimacy to tax the population by incorporating religion into the constitution, i.e. theocracy. Here, providing religion to the religious fraction of the society allows the state to make up for losses brought about by decreased exports or devaluation of their natural resources.

In the spirit of Acemoglu, et al. (2001), we highlight the division between groups in the society with different preferences through an episode of conflict that determines the optimal tax regime. The government uses tax revenues to provide religious goods and services. The population is divided into two groups: the materialists and the religious. The materialists are averse to taxes as they do not benefit from religious beliefs, whereas the religious defend taxes as they also enjoy ideological non-pecuniary 
gains fulfilled through a religious state. The capacity of imposing the preferred policy is determined by their de facto power, where the more powerful group implements its preferred policy. One novel feature of the confrontation is that unlike a rebellion against the state, one group loyal to the government principles defends the tax policy, whereas an opposition materialistic group disputes to have the taxes abolished. The intended side-effect of sanctions is to reduce national welfare. This could cause a rise in popular discontent and push the outcome of contest between the two sides of the population against the interests of the regime. We show however that ideological beliefs such as religion in a country can empower the leader by conveying legitimacy to the state. It allows them to raise tax collection as response to sanctions by carving religious ideology into their constitution more firmly. The incumbent must keep the loyal group content to serve as a shield to protect the government's political position.

The degree to which religion can be used as an instrument of resilience against sanctions depends on an exogenous economic state observed at the beginning of each period. When the state of nature is such that the rents and income are more vulnerable to sanctions, the incumbent may find it optimal to moderate its stance on the policy under question. Alternatively, in better economic conditions religious conservatism can be used to defy sanctions. Although the sender does not have perfect information regarding the state of nature and therefore the magnitude of the economic impact of sanctions, it can use the behavior of the government as a signal. Namely, a move towards religious moderation is perceived as a toning down of the target's stance, whereas a more zealous bond between religion and the state instead sends a signal of resilience. ${ }^{1}$ The quality of the received signal plays a crucial role in the decision whether to impose or lift sanctions. ${ }^{2}$ In the presence of a highly accurate signal of compliance, lifting sanctions results in a win-win solution. Likewise, an accurate signal of resilience through the use of ideological conservatism as a remedy justifies the appropriateness of sanctions. Instead, when the political message conveyed through the signal is weak, the willingness to cooperate is not sufficient to persuade the sender as past information about the economy rules its decision.

Our theory can be put in the context of existing theories that explain the phenomenon of international sanctions. The public choice literature suggests that sanctions work through their impact on the relative political effectiveness of interest groups within the target country (Kaempfer and Lowenberg, 1988). By either diminishing or enhancing the political resources of key groups in the target country, sanctions can alter the alignment of domestic interests and thereby generate a change in policy. In our framework, it is religious beliefs that define the identity of different interest groups and the political cleavage through which sanctions alter the socio-political equilibrium. Moving to the paradoxical conclusions of Drezner (1999)'s conflict expectation model, sanctions are more likely to be imposed against targets with a high expectation for future conflict, which are precisely the states that are less likely to concede. In our framework sanctions are imposed on countries that signal non-cooperative behavior,

\footnotetext{
${ }^{1}$ Levy and Razin (2012) investigate the role of theology and the influence of religious organizations on beliefs in society. ${ }^{2}$ See Levy and Razin (2014).
} 
which are precisely the states resilient against sanctions. Finally, in a world of perfect information, a sanction would never be implemented. If it is deemed effective the threat translates into immediate compliance by the target, and if ineffective then sanctions would never be threatened in the first place (Eaton and Engers, 1999). Our theory contributes to the three branches by bringing together the reaction of an ideologue regime to international sanctions in an environment of conflicting interests within the society and the implications for negotiation efforts by both sides in a world of imperfect information with learning.

In the next section we first introduce the case of Iran as a current example that motivates the study of a possible link between religion and sanctions. Section 3 presents the basics of our model. In Section 4, we solve the internal equilibrium to study the optimal reaction of the target country upon sanctions. The government takes into account the composition of the population with respect to their religious beliefs and loyalty to the system. An analysis of the problem of the sender follows in Section 5 to see how the imposition of sanctions and increased ties between religion and the state reinforce each other. We further find the equilibrium under which compliance (resilience) is followed by lifting (imposing) sanctions. The conclusion discusses robustness and generalizability of the model in relationship to other case studies and explain the importance of religion compared to other ideologies as a tool of resilience against sanctions.

\section{The Case of Iran}

Iran is a nation under the spotlight these days for its renewed negotiation efforts with the West regarding its nuclear program. The aim is to lift the existing economic sanctions, which are not a new phenomenon to the Iranian government and population. Since the 1979 revolution, different types of sanctions have been put to force in order to change the Islamic republic's hostile position towards the West. The sanctions were tightened by the US and increasingly supported by the rest of the world in 2012 leading to a change in the turn of events after Iran's 2013 elections. Iran's geographically strategic position in the Persian gulf makes it a crucial player as the region holds the largest share of the world's oil and gas reserves. The same position makes Iran, at least theoretically, more vulnerable to any type of sanctions. Iran is a rentier state which almost fully relies on oil to run its economy. ${ }^{3}$

Nevertheless, sanctions have not only fallen short of achieving their goals in the case of Iran, but have instead bolstered the regime by further stabilizing their roots and empowering their policies. The most plausible instrument in the hands of the Islamic republic is exactly what the name suggests: religious ideology which unites the government and the religious fraction of the population in keeping the concept of religion in the state. Our model can be used to explain that as long as the ideology is strong among the population, sanctions fail. This is in line with Hakimian (2012) stating that ideologue regimes

\footnotetext{
${ }^{3}$ See Bjorvatn and Selvik (2008) and Bjorvatn, Farzanegan and Schneider (2013) for analyses of political competition and rent-seeking within the system for the specific case of Iran.
} 
like Iran tend to have a high pain threshold and may be willing to take a big hit against their population without yielding their international stance. Only upon extreme economic hardship a government may be obliged to alter its behavior. For example, worldwide sanctions against Iran had a surprising and immediate success after the expansive EU sanctions came into effect in July 2013. A policy of threats has since been replaced by a policy of smiles in order to signal the nation's sincerity towards cooperation. Can this be by chance, or can the logic be explained by an arithmetic interaction between the West, the state of Iran, and the population? According to president Rouhani, "international politics is no longer a zero-sum game but a multi-dimensional arena where cooperation and competition often occur simultaneously" (Rouhani, 2013).

Iran can influence the perception of the rest of the world by its actions. The economic and financial environment in Iran have had an ambiguous character as the relevant figures are at times not reported to international organizations or even within the country. The West must therefore evaluate the circumstances through signals sent from Iran's part. A clear form of a signal of moderation can be deduced from the President in power. Other forms of signal are the choice of the negotiation team, their foreign policy during the negotiations (or English proficiency), and the degree of conservatism in internal policies. The recently elected president of Iran, with a relatively more moderate approach than his predecessor, has announced that he has carte blanche regarding the diplomacy with the West to reach a solution with the aim to dissolve the existing sanctions. President Rouhani's carte blanche, for example, serves as a signal of a softening trend in Iran's stance in the negotiations. These initiatives are designed to build a certain degree of trust, and could be viewed positively by the rest of the world depending on the accuracy of the signal. Lifting sanctions in a framework of asymmetric information may therefore occur if Iran's signal succeeds in switching the policy of the West.

\section{Model}

This section introduces the basics of a general model of sanctions, where the world consists of a target country, composed of citizens and an incumbent government, plus the imposing country, to which we refer to as the sender hereafter. As a result of a disagreement between the two sides, the sender is in

the position to put potential sanctions on the target country to create hardship and force the regime to cave into pressure and change behavior. The goal of economic sanctions is in general thought to be to achieve an objective by means of reducing government rents, as well as the standards of living in order to provoke rebellion or social implosion by creating discontent among the population. This can be achieved for instance through a reduced (limited) exports of natural resources (oil), a devaluation of the currency, increased inflation, or the unavailability of certain consumption goods (Farzanegan, 2013).

Time is discrete and infinite, indexed by $t \geq 1$. At time $t$, there exist two possible exogenous states of nature $x_{t} \in\{0,1\}$ that govern the magnitude of the economic impact of sanctions, which in 
essence determine the intentions of the target country whether or not to comply. In a bad economic state of nature, $x_{t}=0$, costs of conceding is lower than the potential damages from sanctions, whereas the opposite holds for $x_{t}=1$. On reasonable ground, only the target country has perfect access to this information. The sender instead speculates the state of nature by observing the persistency of the phenomenon, $\rho_{i}$, assumed for simplicity to be Markovian and dependent of the current state, i.e., $\operatorname{Pr}\left(x_{t}=i \mid x_{t-1}=i\right)=\rho_{i}{ }^{4}$

A policy decision $s_{t} \in S_{t}$ on whether or not to impose a sanction is taken by the sender at time $t \in\{1, \ldots, T\}$. We limit the analysis to the case where the option is binary, i.e. $S_{t} \in\{0,1\}$. The utility derived by the sender from the implementation of a sanction is assumed to be state-dependent so that the policy action $s_{t}=1$ is preferred in state of the world $x_{t}=1$, while the opposite $s_{t}=0$ is true for the state $x_{t}=0$. Since the sender cannot fully perceive the potential effect of sanctions, its preferences can be represented by the following von Neumann-Morgenstern utility function:

$$
W\left(s_{t}, x_{t}\right) \Longleftrightarrow\left\{\begin{array}{l}
1 \text { if } s_{t}=x_{t}, \\
0 \text { otherwise. }
\end{array}\right.
$$

The utility function in (1) captures the loss brought about by a wrong decision or symmetrically the value of a correct decision. The main objective is thus to implement the appropriate policy in terms of sanctions which amounts to guessing the target country's intentions to cooperate. This could, for example, apply to a resolution of a stand-off being good for the whole world $\left(s_{t}=0, x_{t}=0\right)$, or a walk-out by the target country from any potential negotiation followed by activities potentially harmful for the world even if this was not its original intentions $\left(s_{t}=1, x_{t}=0\right)$. In addition, implementing sanctions $\left(s_{t}=1\right)$ entails a cost, $c \in[0,1]$, to the imposing side. This could for instance reflect reduced trade or high prices of natural resources (oil) as a result of reduced access precisely due to sanctions (Farmer, 2000).

Following Coşgel and Miceli (2009), we characterize the role of ideology by focusing on the provision of religion by the state. We extend their framework to a political economy setting by dividing the society into two segments, the materialistic type $A$ and the religious type $B$, comprising a fraction $1-\lambda$ and $\lambda$ of the total population (normalized to one) respectively. Type $A$ only derives utility from composite consumption $C$, whereas the utility of type $B$ also contains a non-pecuniary component to which we refer to as religious ideology. This group supports and gains from the supply of religious laws, goods and services $\xi$ by the government. The utility of a representative agent in each group at time $t$ is therefore given by:

$$
\begin{gathered}
U_{t}^{A}=C_{t}, \\
U_{t}^{B}=C_{t}+u\left(\xi_{t}\right),
\end{gathered}
$$

\footnotetext{
${ }^{4}$ We assume a positive initial probability $\operatorname{Pr}\left\{x_{1}=i\right\}=\rho$ of starting in one state of nature or the other.
} 
where $u^{\prime}>0, u^{\prime \prime}<0$. The utility of the religious group is increasing in the fact that their (religious) ideology is backed by the government. Each citizen is endowed with wealth (income) $Y_{t}(s)$, where $\frac{\partial Y_{t}(s)}{\partial s}<0$ represents the burden of sanctions on the people. An amount $T_{t}$ of income is expropriated by the government as taxes so that:

$$
C_{t}=Y_{t}(s)-T_{t}
$$

The type $A$ agents prefer not to pay any taxes as they do not benefit from the provision of religion by the state.

A pool of politicians, as a representative government, maximize national income in terms of rents, $R_{t}(s)$, where $\frac{\partial R_{t}(s)}{\partial s}<0$ represents the burden of sanctions on the state, as well as taxes expropriated from the population $T$. Consequently, the utility of the government at time $t$ adds up to

$$
V_{t}=R_{t}(s)^{\alpha}\left[T\left(1-\delta\left(\lambda \xi_{t}\right)\right)\right]^{1-\alpha}-\gamma\left(\xi_{t}\right),
$$

where $\gamma\left(\xi_{t}\right)$ is the cost of providing religious goods to the society, and $\alpha$ represents the importance of the two sources of income, rents and taxes respectively. A rentier state would for example more dependent on rents and less on a tax system. Additionally, in the spirit of Cosgel and Miceli $(2009), \delta\left(\lambda \xi_{t}\right) \in[0,1]$ is the cost of taxation in terms of enforcement due to the resistance of citizens having their property confiscated. Here, this cost is lower the more religion provides legitimacy for taxation, or when a higher proportion of the population is religious oriented: $\delta_{\xi_{t}}<0, \delta_{\lambda}<0$. The government optimizes its stance by partially taking into account the necessities of the society. Its agenda therefore includes elements that are contingent on the economic conditions brought about as a consequence of sanctions. Thus, depending on whether sanctions have a potentially high or low impact on the economy, i.e. on rents and income, they assess the economic state of nature that prevails in $t: x_{t}=1$ reflects prosperous economic conditions and resilience against sanctions and $x_{t}=0$ depicts economic hardship and vulnerability to sanctions, such that $\left.\left|\frac{\partial R_{t}(s)}{\partial s}\right|_{x_{t}=0}|>| \frac{\partial R_{t}(s)}{\partial s}\right|_{x_{t}=1} \mid$ and $\left.\left|\frac{\partial Y_{t}(s)}{\partial s}\right|_{x_{t}=0}|>| \frac{\partial Y_{t}(s)}{\partial s}\right|_{x_{t}=1} \mid$.

Prior to the decision at each time $t$, the sender receives an imperfect signal $r_{t} \in\{0,1\}$ related to a change in the extent to which religion is merged with the state, or the level of theocracy. Namely,

Definition 1 A move towards more conservative ideologies (an increase in $\xi_{t}$ ) is perceived by the sender as lower intentions to comply $\left(r_{t}=1\right)$, whereas a step towards religious moderation (a lower $\left.\xi_{t}\right)$ brings an optimistic signal of $r_{t}=0$.

Definition 1 states that an increase in the objectionable policy of the target country is viewed by the sender as a signal of defiance. More conservative ideologies here is viewed as extremism as it entails expropriation from the population, discrimination in the society, and thereby a stubborn response to the conditions set by the sender to lift sanctions. This signal is drawn from a state-dependent Bernoulli distribution and is independent conditional on the current state with the following stochastic property: 


$$
\begin{aligned}
& \operatorname{Pr}\left\{r_{t}=i \mid x_{t}=i\right\}=\mu \text { for } i \in\{0,1\}, \\
& \operatorname{Pr}\left\{r_{t}=i \mid x_{t} \neq i\right\}=1-\mu \text { for } i \in\{0,1\}
\end{aligned}
$$

depicting the informational environment and $\mu$ defines the quality (accuracy) of the signal, assumed to be bounded, i.e. $\mu \in[0,1]$.

The timing of the events in each period $t$ is as follows:

1. Nature decides the economic state $x_{t}$ (i.e., good or bad economic conditions).

2. The target observes the state of nature and chooses the optimal level of religious ideology in the state $\xi_{t}$.

3. The two parts of the society confront to implement their preferred policy.

4. The sender evaluates the signal sent by the target country and decides whether to impose or lift sanctions.

\section{The Target Country}

\subsection{Confrontation among the Population}

We analyze a situation in which the target government attempts to compensate the losses in the value of its natural resources caused by sanctions through tax expropriation. The incumbent is however constrained to keep the faction in favor of religious offerings sufficiently well-off for the taxation to go through. We refer to this minimum satisfactory level of utility that keeps type $B$ loyal to the state as $\bar{U}$. The government must hence maximize utility given the participation constraint of the religious type:

$$
U_{t}^{B}>\bar{U} \geq Y_{t}(s)
$$

where the first inequality secures the loyalty of the group devoted to religion in defending the government and its taxation practices against potential opposition by the rest of the population. In this set-up, note that the materialists never reach the minimum utility level $\bar{U}$ and are therefore always resistant to contribute to the government, i.e. $U_{t}^{A}<\bar{U} \Rightarrow U_{t}^{A}<U_{t}^{B}$. This ensures that due to a rise of ideology within the country (as a result of the optimal policy), the religious type $B$ is always satisfied to defend the policy against type $A$. Remaining silent results in the success of the materialists in changing the government policy and switching to an environment without taxation and religion provision by the state, which yields an equal utility for the whole population equal to their income: $U_{t}^{A}=U_{t}^{B}=Y_{t}(s)$. It thus guarantees that their utility post-confrontation is higher than what it would be if they remain passive since $u\left(\xi_{t}\right)>T_{t}$. 
If the participation constraint (6) is satisfied, the two sides of the population meet to implement their preferred policies after the level of state-provided religion, $\hat{\xi}_{t}$, is decided at the beginning of each period. ${ }^{5}$ We assume that the power of the two sides is represented by a linear contest success function $F_{t}$ proportional to their size and their well-being: $F_{t}^{A}\left(\lambda, U_{t}^{A}\right)=(1-\lambda)\left(\bar{U}-U_{t}^{A}\right)$ and $F_{t}^{B}\left(\lambda, U_{t}^{B}\right)=\lambda\left(U_{t}^{B}-\bar{U}\right)$ respectively. Prospects of success of each group is increasing in its own size, i.e. $\frac{\partial F_{t}^{A}(.)}{\partial \lambda}<0, \frac{\partial F_{t}^{B}(.)}{\partial \lambda}>0$. In addition, group $A$ has more incentives to change the tax policy the further away it puts them from $\bar{U}$, and group $B$ has more incentives to protect the policy the more benefits it brings them with respect to $\bar{U}$. In other words, a lower $U_{t}^{A}$ provokes type $A$ to fight more viciously in a confrontation, whereas a higher $U_{t}^{B}$ induces type $B$ to stand more strongly against them to protect the status quo. More precisely, the definitions of $U_{t}^{A}$ and $U_{t}^{B}$ from (2) reveal that more ideology $u\left(\xi_{t}\right)$ increases the incentives of the religious to defend the dual system of taxes and religious provision by the state, whereas a lower income $Y_{t}(s)$ increases the discontent of both groups due to the lower consumption possibilities. A reduced $Y_{t}(s)$ therefore increases the incentives of the materialists to challenge and decreases the inspiration of the religious to stand against them. The properties of the contest success function can be summarized as $\frac{\partial F_{t}^{A}(.)}{\partial Y_{t}(s)}<0, \frac{\partial F_{t}^{B}(.)}{\partial Y_{t}(s)}>0, \frac{\partial F_{t}^{B}(.)}{\partial u\left(\xi_{t}\right)}>0$. Thus, the second constraint faced by the government when optimizing the level of religion provision is

$$
F_{t}^{B}\left(\lambda, U_{t}^{B}\right) \geq F_{t}^{A}\left(\lambda, U_{t}^{A}\right) .
$$

Whether sanctions succeed or fail therefore depends on how $F_{t}^{A}\left(\lambda, U_{t}^{A}\right)$ and $F_{t}^{B}\left(\lambda, U_{t}^{B}\right)$ are affected with the imposition of sanctions and whether the condition in (7) is feasible. $F_{t}^{B}($.$) is more likely$ to surpass $F_{t}^{A}($.$) when (i) the proportion of the population who are religious, \lambda$, is large, (ii) the extent to which they appreciate religion or their level of beliefs, $u\left(\xi_{t}\right)$, is high.

\subsection{The Provision of Religion by the State}

At the beginning of each period $t$, the government sets the optimal level of religion. First, equality in (7) gives a level of taxation equal to

$$
T_{t}=Y_{t}(s)+\lambda u\left(\xi_{t}\right)-\bar{U}
$$

Taking both participation and incentive constraints into account, the government problem can be written as:

$$
\begin{gathered}
\max _{\xi_{t}} R_{t}(s)^{\alpha}\left[T\left(1-\delta\left(\lambda \xi_{t}\right)\right)\right]^{1-\alpha}-\gamma\left(\xi_{t}\right) \\
\text { s.t. } F_{t}^{B}\left(\lambda, U_{t}^{B}\right) \geq F_{t}^{A}\left(\lambda, U_{t}^{A}\right), \\
U_{t}^{B}>\bar{U} .
\end{gathered}
$$

\footnotetext{
${ }^{5}$ See Gershenson (2002) for an alternative framework in which sanction influences civil conflict in a target country.
} 
According to (9), the government must decide to what extent religion provision must be executed by the state. It follows that:

$$
\hat{\xi}_{t} \Rightarrow \underbrace{-\frac{\partial s_{t}}{\partial \xi_{t}}\{\underbrace{\frac{\partial R_{t}(s)}{\partial s} \frac{\alpha}{(1-\alpha)} \frac{T_{t}\left(1-\delta\left(\lambda \xi_{t}\right)\right)}{R_{t}(s)}}_{\text {effect of sanction on rents }}+\underbrace{\frac{\partial Y_{t}(s)}{\partial s}\left[1-\delta\left(\lambda \xi_{t}\right)\right]}_{\text {effect of sanction on income }}\}}_{\text {changing probability of sanctions being imposed or lifted }}+\gamma^{\prime}\left(\xi_{t}\right)=\underbrace{\lambda\left\{u^{\prime}\left(\xi_{t}\right)\left[1-\delta\left(\lambda \xi_{t}\right)\right]-T_{t} \delta^{\prime}\left(\lambda \xi_{t}\right)\right\}}_{\text {religiosity }} .
$$

$\mathbf{P}$ roof. See the Appendix.

Marginal costs and marginal benefits of providing religion must be equal. The left-hand-side indicates the state's marginal cost of religious provision through its relevance in provoking sanctions $\left(\frac{\partial s_{t}}{\partial \xi_{t}}\right)$ and its subsequent impact on rents and income, while the right-hand-side contains the marginal benefits of religion that arise from increasing the utility of the religious type and facilitating taxation. If the marginal costs of providing an additional unit of religion is higher (lower) than its marginal benefits, then it is optimal to introduce a more moderate (conservative) ideology by the state. The magnitude of the marginal costs depends on the economic state of nature revealed in the first stage of the game. It also depends on the probability that religion can play a role in influencing the policy of sanctions, which is directly correlated with $\mu$ from (5). Examining (10) reveals some comparative statics that are summarized in the following Lemma:

Lemma 1 It is more costly to increase the provision of religious ideology by the state when (i) religion is highly relevant in the decision of the sender to impose sanctions, high $\frac{\partial s_{t}}{\partial \xi_{t}}$, (ii) the economic state in the target has revealed $x_{t}=0$, high $\frac{\partial R_{t}(s)}{\partial s}$ and $\frac{\partial Y_{t}(s)}{\partial s}$, (iii) there is high dependence on natural resource (oil) rents, high $\alpha$. Providing religion is instead more beneficial when (i) there is a large effect of religion on the utility of type $B$, high $u^{\prime}\left(\xi_{t}\right)$, (ii) there is a large effect of religion on facilitating tax collection, high $\delta^{\prime}\left(\lambda \xi_{t}\right)$, (iii) a high proportion of the society is religious, high $\lambda$.

$\mathbf{P}$ roof. Follows directly from expression (10).

\subsection{The Impact of Sanctions}

We start by observing that incentive and the participation constraints in (6) and (7) must be satisfied for ideology to play an active role in the first place. We can therefore state:

Lemma 2 Religious provision by the state can be used as a tool for resilience against sanctions when the proportion of the religious type in the country, $\lambda$, or the intensity of their religious values $u\left(\xi_{t}\right)$ are large. 
$\mathbf{P}$ roof. Looking at conditions (6) and (7), and the definitions of the contest success functions $F_{t}^{A}\left(\lambda, U_{t}^{A}\right)=(1-\lambda)\left(\bar{U}-U_{t}^{A}\right)$ and $F_{t}^{B}\left(\lambda, U_{t}^{B}\right)=\lambda\left(U_{t}^{B}-\bar{U}\right)$, we can see that they can only be satisfied in the presence of a large $\lambda$ and/or a large $u\left(\xi_{t}\right)$.

Sanctions can instead be deemed effective in societies in which ideologies such as religion do not have a significant role in the population and the state, that is, where $\lambda$ and $u\left(\xi_{t}\right)$ take a low value. ${ }^{6}$ If this is the case, the government is unable to collect taxes and would not find it optimal to provide religion as long as $\gamma\left(\xi_{t}\right)>0$. To see this suppose a simple setting in which $\hat{\xi}_{t} \approx 0$. In this case there is no reason for the religious to engage in conflict to protect the government because they would not find it optimal to engage in confrontation for any $T_{t}>0$. Here, ideology does not have an added value, it cannot be used as a device against sanctions and the tax policy cannot be legitimized. This is the only case in which sanctions are perfectly effective independent of the state of nature as they equally create hardship among the whole population leading to cooperation.

At times of sanction the government compensates the religious group with religion to make up for their material loss. This is more convenient when a higher proportion of the society is religious. Likewise, religion is a more powerful tool when $u\left(\xi_{t}\right)$ is high, otherwise it may be optimal to reduce religion to give a signal of cooperation as a consequence of sanctions. To see the effect of sanctions in the target country, first recall that $U_{t}^{B} \geq U_{t}^{A}$ is true as long as taxes are levied and religion is implemented by the state, i.e. when $T_{t}\left[1-\delta\left(\lambda \xi_{t}\right)\right]>\gamma\left(\xi_{t}\right)$. Since $\bar{U}$ is constant, a reduction in $Y_{t}(s)$ in (2) due to sanctions must be compensated by providing a higher level of religion to increase $u\left(\xi_{t}\right)$. This is the only way to maintain the loyalty of the group devoted to religion in confronting the rest of the population to defend the government in power and its taxation practices. Sanctions are therefore likely to trigger an increase in the provision of religion in order to make up for the direct losses in natural resource (oil) revenues through taxation.

Proposition 1 A reduction in rents and income brought about by sanction can be offset by increasing the level of religious provision by the state in order to use expropriation as an alternative source of revenues.

$\mathbf{P}$ roof. An increase in the LHS of (10) from $\frac{\partial s_{t}}{\partial \xi_{t}} \frac{\partial Y_{t}(s)}{\partial s}$ and $\frac{\partial s_{t}}{\partial \xi_{t}} \frac{\partial R_{t}(s)}{\partial s}$ is offset by benefits of religion on the RHS through a rise in the utility of the religious population, $u^{\prime}\left(\xi_{t}\right)$, and more taxation brought about by increased legitimacy, $T_{t} \delta^{\prime}\left(\lambda \xi_{t}\right)$.

By observing the impact of sanctions on the economy, the government finds itself in one of the two states of nature and evaluates the benefits of religion provision given the impact of sanctions. The impact

\footnotetext{
${ }^{6}$ Associating the aggregate level of secularism in the target country with development would imply that such mechanism would be stronger in less developed countries (higher $u\left(\xi_{t}\right)$ ). Similarly, a positive relation between religious beliefs and poverty would suggest a more important role for ideology when the proportion of the poor is large in the society (higher $\lambda)$.
} 
suggested in Proposition 1 is more intensive when the state of nature reveals a good economic situation, $x_{t}=1$, so that sanctions do not drastically decrease rents and income. Under such circumstances costs of expanding religious services are not so high. In this way religion can be used to legitimize taxation in a country where religious ideology has deep roots in the society. On the contrary, under an undesirable state of nature, $x_{t}=0$, reducing religion is the optimal choice by the government to avoid further sanctions.

Proposition 2 When sanctions have a small economic impact (low $\frac{\partial R_{t}(s)}{\partial s}$ and $\left.\frac{\partial Y_{t}(s)}{\partial s}\right)$, it is easier to use religious ideology as an instrument to adapt by restoring losses in rents through taxation. When sanctions are detrimental to the economy (high $\frac{\partial R_{t}(s)}{\partial s}$ and $\left.\frac{\partial Y_{t}(s)}{\partial s}\right)$, it is more convenient to reduce religious provision to increase the probability of having sanctions lifted.

$\mathbf{P}$ roof. See (10) and Lemma 1.

Recall from Definition 1 that a subsequent reduction (increase) in taxation $\left(T_{t}\right)$ and religion $\left(\hat{\xi}_{t}\right)$ produce a signal of religious moderation (conservatism) $r_{t}=0\left(r_{t}=1\right)$ for the sender, who moves next to choose its optimal policy regarding sanctions.

\section{The Imposing Country}

We now turn to the problem of the sender to explore the link between sanctions and the level of state ideology in an international context. We denote $\kappa_{t}(r)=\left\{r_{1}, \ldots, r_{t-1}\right\}$ as the signals sent by the target country in the past and $\kappa_{t}(s)=\left\{s_{1}, \ldots, s_{t-1}\right\}$ as the sender's actions in previous periods. Suppose that $p_{t} \equiv \operatorname{Pr}\left(x_{t}=1 \mid \kappa_{t}(r), \kappa_{t}(s)\right)$ is the prior belief that the state of the economy in the target country is strong in period $t\left(x_{t}=1\right)$ conditional on the observed history of actions and signals. Similarly, let $\tilde{p}_{t}\left(r_{t}, p_{t}\right) \equiv \operatorname{Pr}\left(x_{t}=1 \mid \kappa_{t}(r), \kappa_{t}(s), r_{t}\right)$ be the posterior belief that the exogenous state is $x_{t}=1$ after the realization of the signal, $r_{t}$. The posterior is used to compute the expected payoffs of the two potential actions in the two states. The sender chooses an action $s_{t}$ which gives the highest payoff given the cost of implementing sanctions, $c$. When the sender receives the signal $r_{t}=1$, it is optimal to impose a sanction $\left(s_{t}=1\right)$ if and only if $\tilde{p}_{t}>c$.

Using a simple application of Bayes' rule, the sender's decision can be expressed according to the prior belief $p_{t}$ :

Proposition 3 In any period $t$,

- for $p^{-} \leq p_{t} \leq p^{+}, s_{t}=1$ if and only if $r_{t}=1$,

- for $p_{t}>p^{+}, s_{t}=1$ independent of $r_{t}$, 
- for $p_{t}<p^{-}, s_{t}=0$ independent of $r_{t}$,

where

$$
p^{-}=\frac{(1-\mu) c}{(1-\mu) c+\mu(1-c)} \quad \text { and } \quad p^{+}=\frac{\mu c}{\mu c+(1-\mu)(1-c)} .
$$

$\mathbf{P}$ roof. See Appendix.

Proposition 3 shows that the new information provided by the signal is irrelevant in altering the policy of the sender if the prior is sufficiently high (low) such that $p_{t}>p^{+}\left(p_{t}<p^{-}\right){ }^{7}$ Alternatively, there exists a learning mechanism if $p^{-} \leq p_{t} \leq p^{+}$such that the decision reflects the $t$-period information $\left(s_{t}=r_{t}\right)$. Since the state of nature is randomly assigned in each period, the main task of the sender is to correctly predict the appropriateness of sanctions. The accuracy of the signal sent by the target country, $\mu$, determines the reliability of the new information revealed in period $t$, and hence the size of the learning area introduced in Proposition $3{ }^{8}$ This range expands in $\mu$, and shifts to the right with $c$. Together with the persistence of the state of nature, $\rho_{i}$, and $c$, accuracy determines the sender's action such that

Proposition 4 When the quality of the signal sent by the target is sufficiently high, i.e. $\mu>\hat{\mu}\left(\rho_{i}, c\right)$, the sender decides based on current information (i.e. $p^{-} \leq p_{t} \leq p^{+}$).

$\mathbf{P}$ roof. See Appendix.

We can deduce from Proposition 4 that a sufficiently accurate signal can overcome the role of persistency of the state of the economy in the sender's policy and persuade it to act based on the target's behavior. We can now establish an equilibrium in which the two players optimally choose their actions:

Proposition 5 When $\mu>\hat{\mu}$, learning always generates a win-win strategy in a perfect Bayesian equilibrium:

$$
\begin{aligned}
& \text { (a) } x_{t}=1 \Longleftrightarrow\left(\hat{\xi}_{t}^{1} ; r_{t}=1 ; \mu>\hat{\mu}\right) \Rightarrow \quad p^{-} \leq p_{t} \leq p^{+} \text {such that } s_{t}=1, \\
& \text { (b) } x_{t}=0 \Longleftrightarrow\left(\hat{\xi}_{t}^{0} ; r_{t}=0 ; \mu>\hat{\mu}\right) \Rightarrow \quad p^{-} \leq p_{t} \leq p^{+} \text {such that } s_{t}=0,
\end{aligned}
$$

where we denote $\hat{\xi}_{t}^{1}$ and $\hat{\xi}_{t}^{0}$ as the optimal level of religion respectively in state $x_{t}=1$ and $x_{t}=0$, and $\hat{\xi}_{t}^{1}>\hat{\xi}_{t}^{0}$.

$\mathbf{P}$ roof. The proof directly derives from Proposition 4 .

Proposition 5 points out that conditional on the state of nature, $x_{t}$, the optimal level of religion $\hat{\xi}_{t}^{i}$ truly reveals the prevailing state of the economy $\left(r_{t}=x_{t}\right)$. If the sender perceives this as a sufficiently

\footnotetext{
${ }^{7}$ This is referred to as an informational cascade. See Banerjee (1992) and Bikhchandani, et al. (1992).

${ }^{8}$ See Moscarini, et al. (1998) for more on the mechanism of social learning in a changing world.
} 
accurate signal $(\mu>\hat{\mu})$, it revises its beliefs in accordance with the signal received. In this equilibrium the sender gets the maximum payoff since $s_{t}=x_{t}$, while the target country obtains the highest utility from rents and taxation based on its optimization process. Hence, we denote it as a win-win strategy.

We can conclude that the sender and the target country can reach a win-win equilibrium, given rational behavior by the two sides of the negotiation table. First of all, this setting generates a truthtelling mechanism since the target country never conveys a false signal regarding the state of nature, $x_{t}$, as the latter closely corresponds to its optimal level of religious conservatism $\hat{\xi}_{t}$. It immediately follows that if the target makes a move towards a more moderate ideology, lifting the sanctions is the only move by the sender that can achieve a win-win solution. Similarly, and perhaps paradoxically, a win-win solution can also be reached through a combination of sanctions and resilience.

The learning equilibrium clearly implies that the relevance of information provided by the signal is so high in expected terms that it overcomes the impact of persistency in the state of the economy, $\rho_{i}$. On the contrary, when the latter dominates the effect of the signal, there is no guarantee that the prior of the sender correctly corresponds to the current state of nature:

Proposition 6 The sender neglects the signal at time $t$ and decides based on past information when $\mu<\hat{\mu}$. If the prevailing situation is sanctions, then

$$
\begin{aligned}
& \text { (a) } x_{t}=1 \Longrightarrow\left(\hat{\xi}_{t}^{1} ; r_{t}=1 ; \mu<\hat{\mu}\right) \Rightarrow p_{t}>p^{+} \text {such that } s_{t}=1, \\
& \text { (b) } x_{t}=0 \Longrightarrow\left(\hat{\xi}_{t}^{0} ; r_{t}=0 ; \mu<\hat{\mu}\right) \Rightarrow p_{t}>p^{+} \text {such that } s_{t}=1 .
\end{aligned}
$$

$\mathbf{P}$ roof. The proof directly derives from Proposition 4.

The idea behind Proposition 6 is that although sending an accurate signal is in the interest of the target country in every period, persistency of the state of nature can work as a force against learning. Here, the sender imposes sanctions irrespective of the signal sent. This action can be the right strategy if $x_{t}=1$. Nonetheless, if the current state of nature deteriorates to $x_{t}=0$ (after several episodes of $x=1$ ), then an accurate signal of $r_{t}=0$ fails to persuade the sender to lift sanctions as persistence of resilience contracts the learning equilibrium range. A similar concept holds for $p_{t}<p^{-}$, where the sender never impose a sanction, i.e., $s_{t}=0$, regardless of the signal received.

Figure 1 summarizes Propositions 3-6 and shows the outcome for all combinations of the prior and the state of nature. Looking at the thresholds $p^{+}$and $p^{-}$the figure shows how the learning interval can expand with $\mu$ and shift to the right with $c$. The win-win equilibrium takes place in the center region of the figure, where the target gives up its objectionable policy to avoid sanctions through diplomacy or sanctions follow as a response to a gesture of defiance. The side regions represent the cases where the sender's decision is based on past information about the state of the economy. On the left, the 


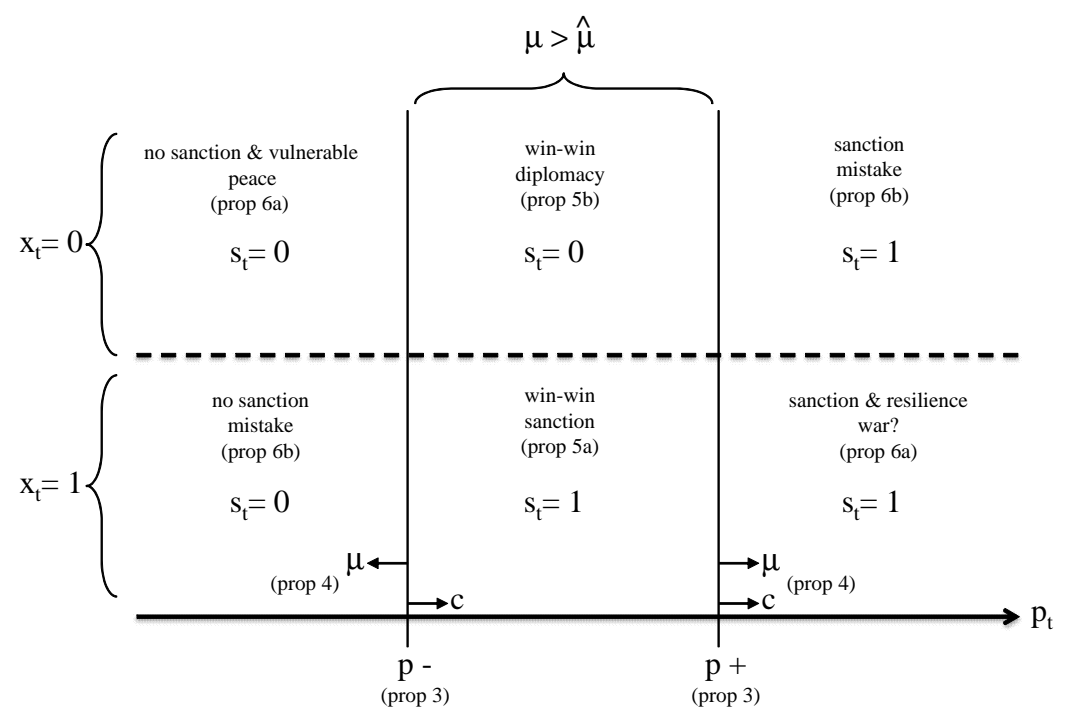

Figure 1: Sanctions, Diplomacy, and Resilience

expectation of vulnerability results in no sanctions, which could be the correct decision when $x_{t}=0$ and misplaced if $x_{t}=1$. Alternatively, sanctions are always in place on the right side due to the persistence of resilience either as an untimely policy when $x_{t}=0$ or the correct form of punishment if $x_{t}=1$.

Finally, the analysis falls short of assessing additional options on the table due to the simple binary nature of the sender's utility function. If for example the choice of military attack is incorporated into the model, it would only be reasonable in a situation of stalemate under persisting resilience and sanctions $\left(x_{t}=1 ; s_{t}=1\right)$ at the bottom right of the figure. Here the opportunity cost of continuous (ineffective) containment through sanctions amounts to a one-shot military action that may achieve the job and reduce the risk faced in future periods. In the present model, however, committing a mistake could be very costly, perhaps more than sanctions, since the current state of nature is unobservable. ${ }^{9}$

\section{Concluding Discussion}

Our research has explored how the potential consolidation of religion and state in a theocracy governs the outcome of economic sanctions. In so doing, we showed situations under which political instruments such as sanctions increase the magnitude and the persistence of religious ideology in the target country. In a rentier state, leaning towards such ideology facilitates the regime's task of rent extraction as a substitute

\footnotetext{
${ }^{9}$ The sender would suffer a loss if it attacks when the target is ready to comply, that is when $x_{t}=0$.
} 
for the sanction-caused reduction in rents. Additionally, resorting to religion buys the sympathy of the religious population, replacing their material loss caused by sanctions with religion and the realization of their beliefs. This allows the state to strengthen its defense, against the world and its own population, and at the same time increase their support within the population. A sanction therefore may at times defeat its own purpose by strengthening the regime in power. The model reveals that signals sent by a target country play a crucial role in the decision of imposing or lifting a sanction and leads to a stable equilibrium over time.

The political economy model applied in the paper is set to capture the political system in a theocratic state. When religion plays an important part in the role of the state, decisions about the magnitude of its involvement in policy decisions over time are made endogenously by the ruling regime. National rents belong to the government, whereas the interest of the population is directed on their income. In addition, a proportion of the population who share the government's ideology enjoy the support of the government and in return provide protection to the government policies. In other words, a potential conflict is not motivated by capturing the national rents, but to create circumstances that would improve individual welfare. The two parts of the society therefore meet to implement their preferred policy, whereas the state balances their power to create stability. Nevertheless, our results remain robust under a different theoretical set-up more similar to Acemoglu et al. (2001), where an uprising could lead to the ousting of the incumbent regime.

The most extensive data on economic sanctions is provided in Hufbauer et al. (2007), who argue that sanctions work one-third of the time. Proponents of the use of sanctions argue that economic pressure can help achieve desirable goals while avoiding the high costs of military intervention (Baldwin, 1985). Economic pressure typically takes place alongside other important events and developments, such as a weak economy. Here diplomacy is an alternative option overlooked in the literature, which could practically even avoid the cost of sanctions if they succeed to prevent the target from carrying out its objectionable policy. The history of sanctions hints that there is no unique equilibrium to a complex problem as such. It reveals the existence of, and the contemporaneous interplay between, several factors in determining the conduct by each side and the prospective outcome. The simultaneous competition and cooperation in a world of asymmetric information may indeed lead to completely different outcomes.

Societies that are divided or naturally heterogeneous before sanctions may become even more fragmented by the economic effects of sanctions if the economic pain is not equally distributed across groups in society. In response to economic pressures brought about by sanctions, it is natural that at least a part of the population would resort to their elemental non-pecuniary ties that can for example originate from their ethnic, religious, or national identity. Our argument is that a leader can use this heterogeneity to its advantage to increase the pain threshold of the state by promoting the appropriate ideology. In sum, an ideologue regime is therefore more resistant and harder to contain using economic 
sanctions.

Our hypothesis on theocracy can be expanded to other beliefs or other forms of identity. International sanctions could spark a rise in popularity for the target government through the so-called rally around the flag effect (Mueller, 1970). Leaders of these countries can also pinpoint the imposing state(s) as a clear external threat to the nation and therefore a common enemy to unify the state (Miyagawa 1992). There are many concrete examples that can be observed across the world. The U.S. ban on travel and trade with Cuba since 1960 in protest against the turn to communism by Fidel Castro have not induced any major change in Cuba's communist system despite keeping Cuba poor. North Korea has lived with international sanctions since 1950 and the more recent sanctions imposed by the U.N. to discourage it from pursuing its nuclear weapons program and punish it for human rights violations has had little effect on the actions of Kim Jong-Il or his son Kim Jong-Un. Likewise, multilateral sanctions imposed against Iraq after its invasion of Kuwait were quite devastating in terms of their economic impact but were much less effective politically due to fragmentation of the Iraqi opposition. Differently in South Africa, the ethnic minority in power had a vested interest in maintaining the status quo and shielded the white supporters from the pain of sanctions. In this case, sanctions could have played a role, even if small, in putting an end to the apartheid regime because the white community only accounted for a smaller percentage of the population, i.e. violating our Lemma 2.

Although our theory can be applied to any ideology that can help attract loyalty at times of deprivation, religion has a credible history to serve as a substitute for material needs. Where governments and economies function poorly, religion often becomes major suppliers of (i) social services, (ii) political action, and (iii) coercive force at the same time (Iannaccone and Berman, 2006). We therefore believe it can work as a more credible shield against sanctions. We do, however, show that diplomacy can be used as a preferred mode of interaction upon the receipt of the appropriate signal even in the case of a theocracy. Our analysis also leaves room for future research regarding arguments such as the size of the target country and the of severity of sanctions, which could play a large role in the effectiveness of sanctions against countries such as Russia and China. 


\section{A Appendix}

\section{A.1 Government's Optimization Problem}

$$
\begin{gathered}
\alpha R^{\alpha-1}\left[T\left(1-\delta\left(\lambda \xi_{t}\right)\right)\right]^{1-\alpha} \frac{\partial s_{t}}{\partial \xi_{t}} R^{\prime}(s)+(1-\alpha) R(s)^{\alpha}\left[T\left(1-\delta\left(\lambda \xi_{t}\right)\right)\right]^{-\alpha}\left\{\left[\lambda u^{\prime}\left(\xi_{t}\right)+\frac{\partial s_{t}}{\partial \xi_{t}} Y^{\prime}(s)\right]\left[1-\delta\left(\lambda \xi_{t}\right)\right]-T_{t} \lambda \delta^{\prime}\left(\lambda \xi_{t}\right)\right\}-\gamma^{\prime}\left(\xi_{t}\right)=0 \\
\alpha\left(\frac{\left[T\left(1-\delta\left(\lambda \xi_{t}\right)\right)\right]}{R(s)}\right)^{1-\alpha} \frac{\partial s_{t}}{\partial \xi_{t}} R^{\prime}(s)+(1-\alpha)\left(\frac{R(s)}{\left[T\left(1-\delta\left(\lambda \xi_{t}\right)\right)\right]}\right)^{\alpha}\left\{\left[\lambda u^{\prime}\left(\xi_{t}\right)+\frac{\partial s_{t}}{\partial \xi_{t}} Y^{\prime}(s)\right]\left[1-\delta\left(\lambda \xi_{t}\right)\right]-T_{t} \lambda \delta^{\prime}\left(\lambda \xi_{t}\right)\right\}-\gamma^{\prime}\left(\xi_{t}\right)=0 \\
\quad-\frac{\partial s_{t}}{\partial \xi_{t}} R^{\prime}(s) \alpha\left(\frac{\left[T\left(1-\delta\left(\lambda \xi_{t}\right)\right)\right]}{R(s)}\right)^{1-\alpha}-\frac{\partial s_{t}}{\partial \xi_{t}} Y^{\prime}(s)\left[1-\delta\left(\lambda \xi_{t}\right)\right](1-\alpha)\left(\frac{R(s)}{\left[T\left(1-\delta\left(\lambda \xi_{t}\right)\right)\right]}+\gamma^{\prime}\left(\xi_{t}\right)\right. \\
=\quad\left\{\lambda u^{\prime}\left(\xi_{t}\right)\left[1-\delta\left(\lambda \xi_{t}\right)\right]-T_{t} \lambda \delta^{\prime}\left(\lambda \xi_{t}\right)\right\}(1-\alpha)\left(\frac{R(s)}{\left[T\left(1-\delta\left(\lambda \xi_{t}\right)\right)\right]}\right)^{\alpha} \\
-\frac{\partial s_{t}}{\partial \xi_{t}} R^{\prime}(s) \frac{\alpha}{(1-\alpha)} \frac{T\left(1-\delta\left(\lambda \xi_{t}\right)\right)}{R(s)}-\frac{\partial s_{t}}{\partial \xi_{t}} Y^{\prime}(s)\left[1-\delta\left(\lambda \xi_{t}\right)\right]+\gamma^{\prime}\left(\xi_{t}\right)=\lambda u^{\prime}\left(\xi_{t}\right)\left[1-\delta\left(\lambda \xi_{t}\right)\right]-\lambda T_{t} \delta^{\prime}\left(\lambda \xi_{t}\right) \\
\hat{\xi}_{t} \Rightarrow-\frac{\partial s_{t}}{\partial \xi_{t}}\left\{R^{\prime}(s) \frac{\alpha}{(1-\alpha)} \frac{T\left(1-\delta\left(\lambda \xi_{t}\right)\right)}{R(s)}+Y^{\prime}(s)\left[1-\delta\left(\lambda \xi_{t}\right)\right]\right\}+\gamma^{\prime}\left(\xi_{t}\right)=\lambda\left\{u^{\prime}\left(\xi_{t}\right)\left[1-\delta\left(\lambda \xi_{t}\right)\right]-T_{t} \delta^{\prime}\left(\lambda \xi_{t}\right)\right\}
\end{gathered}
$$

\section{A.2 Proof of Proposition 3}

Under Bayes' rule, the $t$-posterior probability $\tilde{p}_{t}$ of imposing sanctions is a function of the past information embedded in the prior belief $p_{t}$ and the new information obtained through the signal $r_{t}$,

$$
\left.\tilde{p}_{t}\left(r_{t}, p_{t}\right)\right|_{s_{t}=i}=\frac{\operatorname{Pr}\left(r_{t}=i \mid x_{t}=i\right) \operatorname{Pr}\left(x_{t}=i \mid \mathbb{k}_{t}\right)}{\operatorname{Pr}\left(r_{t}=i \mid x_{t}=i\right) \operatorname{Pr}\left(x_{t}=i \mid \mathbb{k}_{t}\right)+\operatorname{Pr}\left(r_{t}=i \mid x_{t} \neq i\right)\left(1-\operatorname{Pr}\left(x_{t}=i \mid \mathbb{k}_{t}\right)\right.},
$$

where $\mathbb{k}_{t}$ is defined as the set enclosing the history of signals and actions, respectively $\kappa_{t}(r)$ and $\kappa_{t}(s)$. In particular, given the state $x_{t}=1$, the $t$-posterior probability that a sanction is appropriate, i.e. $s_{t}=1$, is:

$$
\left.\tilde{p}_{t}\right|_{s_{t}=1}=\frac{\mu p_{t}}{\mu p_{t}+(1-\mu)\left(1-p_{t}\right)},
$$

where the optimal choice is realized by comparing $\left.\tilde{p}_{t}\right|_{s_{t}=1}$ and $c$. Similarly, the decision of no sanctions is optimal whenever $\left.\tilde{p}_{t}\right|_{s_{t}=0}>c$.

After some manipulations, we observe that sanctions are surely imposed whenever $p_{t}>p^{+}$, where $p^{+}=\frac{\mu c}{\mu c+(1-\mu)(1-c)}$. We therefore obtain a lower bound prior below which sanctions are not applied whenever $p_{t}<p^{-}$, where $p^{-}=\frac{(1-\mu) c}{(1-\mu) c+\mu(1-c)}$. The two extreme areas, respectively $p_{t}>p^{+}$and $p_{t}<p^{-}$, implicitly suggest that the choice is only guided by past information. In the former case, the optimal strategy is to impose sanctions, independently from the received signal. In the latter case, the optimal choice is refrain from imposing a sanction, whatever is the new information provided by the signal $\mu$. Moreover, there exists a learning space when the prior $p_{t}$ falls within the two bounds, $p^{-} \leq p_{t} \leq p^{+}$. In this case, the $t$-period information provided by the signal, $r_{t}$, systematically overcomes past information from $p_{t}$. Based on the available information, we may summarize the sender's optimal actions as follows:

$$
s_{t}=\left\{\begin{array}{l}
1 \Longleftrightarrow p_{t}>p^{+} \text {or } p^{-} \leq p_{t} \leq p^{+} \text {if } r_{t}=1, \\
0 \Longleftrightarrow p_{t}<p^{-} \text {or } p^{-} \leq p_{t} \leq p^{+} \text {if } r_{t}=0
\end{array}\right.
$$




\section{A.3 Proof of Proposition 4}

In proposition 3, we demonstrate that current information (through signal) is more relevant than past information, whenever $p^{-} \leq p_{t} \leq p^{+}$. Here we claim that this learning area is not fixed, but expands when the accuracy of the signal $\mu$ increases. In particular, we show the sufficient condition for $\mu$, which ensures that the prior of imposing a sanction, $p_{t}$, always falls within learning area. This is possible by relating the impact of persistence of the state of nature $\{0,1\}$ on the bounded beliefs, $p^{+}$and $p^{-}$. Note that the exogenous state of nature at time $t$ is unobservable by the sender, since it can only capture the probability that the state of nature is persistent. Looking at the sender's evaluation of $p_{t}$, we investigate the case when sanction is an appropriate action $\left(s_{t}=x_{t}=1\right)$. The phenomenon from $t-1$ to $t$ is considered persistent when $\operatorname{Pr}\left(x_{t}=1 \mid x_{t-1}=1\right)=\rho_{1}$, and not persistent when $\operatorname{Pr}\left(x_{t}=1 \mid x_{t-1}=0\right)=1-\rho_{0}$. Therefore, for a given cost, $c \in[0,1]$, on one side, $p^{+}=\frac{\mu c}{\mu c+(1-\mu)(1-c)}$ is increasing in $\mu$ such that if $\mu=1$ then $p^{+}=1$. On the other side, $p^{-}=\frac{(1-\mu) c}{(1-\mu) c+\mu(1-c)}$ is decreasing in $\mu$ such that if $\mu=1$ then $p^{-}=0$.

When $\rho_{1}>p^{+}$, the persistence of the state of nature $\left(x_{t}=1\right)$ from $t-1$ to $t$ dominates the prior upper bound. This results when $\mu<\mu_{1}$, where $\mu_{1}=\frac{\rho_{1}(1-c)}{\rho_{1}(1-c)+c\left(1-\rho_{1}\right)}$ and suggests that for a lower level of accuracy, the sender's choice of sanction is entirely guided by information from persistence of the economic state. When $p^{-}<\left(1-\rho_{0}\right)$, instead, it means the probability of the state changing from $t-1$ to $t$ is higher than the prior lower bound. This is possible when $\mu>\mu_{0}$, where $\mu_{0}=\frac{c \rho_{0}}{c \rho_{0}+(1-c)\left(1-\rho_{0}\right)}$, such that the accuracy of the signal is high enough to make current information relevant. Thus, $p_{t} \in\left[p^{-} ; p^{+}\right]$ if and only if $\mu>\hat{\mu} \equiv \max \left\{\mu_{0} ; \mu_{1}\right\}$. This is the sufficient condition ensuring that a learning zone always exists. The higher the persistency $\left\{\rho_{0}, \rho_{1}\right\}$, the higher is the $\mu$ level required for the prior to fall in the learning range. 


\section{References}

[1] Acemoglu, D., Johnson, S. and Robinson, J. A. (2001), 'The Colonial Origins of Comparative Development: An Empirical Investigation', American Economic Review, 91(5), 1369-1401.

[2] Allen, S.H. (2008), 'The Domestic Political Costs of Economic Sanctions', Journal of Conflict Resolution, 52 (6), 916-944.

[3] Baldwin, D. (1985), Economic Statecraft. Princeton, NJ: Princeton University Press.

[4] Banerjee, A. (1992), 'A Simple Model of Herd Behavior', Quarterly Journal of Economics, 107 (3), $797-817$.

[5] Bjorvatn, K.and Selvik, K. (2008). 'Destructive competition: Factionalism and rent-seeking in Iran', World Development, 36(11), 2314-2324.

[6] Bjorvatn, K., Farzanegan, M., and Schneider, F. (2013). 'Resource Curse and Power Balance: Evidence from Iran', Review of Middle East Economics and Finance, 9 (2), 133-158.

[7] Bikhchandani, S., Hirshleifer, D. and Welch, I. (1992), 'A Theory of Fads, Fashion, Custom and Cultural Change as Informational Cascades', Journal of Political Economy, 100(5), 992-1026.

[8] Carvalho, J.P. (2013), 'Veiling', Quarterly Journal of Economics, 128(1), 337-370.

[9] Coşgel, M. and Miceli, T.J. (2009), 'State and Religion', Journal of Comparative Economics, 37, $402-416$.

[10] Coşgel, M. and Miceli, T.J. (2013), 'Theocracy', University of Connecticut Working Paper 2013-29.

[11] Drezner, D. (1999), The Sanctions Paradox. Cambridge, UK: Cambridge University Press.

[12] Eaton, J. and Engers, M. (1999). 'Sanctions: Some Simple Analytics', American Economic Review, 89(2): 409-414.

[13] Farmer, R. D. (2000), 'Costs of Economic Sanctions to the Sender', The World Economy, 23, 1, 93-117.

[14] Farzanegan, M. (2013), 'Effects of International Financial and Energy Sanctions on Iran's Informal Economy', SAIS Review, 33, 1, 13-35.

[15] Gershenson, D. (2002), 'Sanctions and Civil Conflict', Economica, 69, 185-206.

[16] Hakimian, H. (2013), 'Iran's economy is hurting - yet sanctions are not a nuclear deterrent', The Guardian, October 3, 2012. 
[17] Hufbauer, G., Jeffrey, C., Schott, J., Elliott, K.A. and Oegg, B. (2007), Economic Sanctions Reconsidered. 3rd Edition. Washington, DC: Peterson Institute for International Economics.

[18] Iannaccone, L.R. and Berman, E. (2006), 'Religious Extremism: The Good, the Bad, and the Deadly', Public Choice, 128, 109-129.

[19] Johnson, N. and Koyama, M. (2013), 'Legal centralization and the birth of the secular state', Journal of Comparative Economics, 41, 959-978

[20] Kaempfer W.H. and Lowenberg, A.D. (1988), 'The Theory of International Economic Sanctions: A Public Choice Approach', American Economic Review, 78(4), 786-793.

[21] Levy G. and Razin R. (2012), 'Religious Beliefs, Participation and Cooperation', American Economic Journal: Microeconomics, 4(3), 121-51.

[22] Levy G. and Razin R. (2014), 'Rituals or Good Works: Social Signalling in Religious Organizations', Journal of the European Economic Association, 12(5), 1317-1360.

[23] Marinov, N. (2005), 'Do Sanctions Destabilize Country Leaders?' American Journal of Political Science, 49(3), 564-576.

[24] Miyagawa (1992), Do Economic Sanctions Work? New York, NY: St. Martin's.

[25] Moscarini, G., Ottaviani, M., Smoth, L. (1998), 'Social Learning in a Changing World', Economic Theory, 11(3), 657-665.

[26] Mueller, J. (1970), 'Presidential Popularity from Johnson to Truman', American Political Science Review, 63, 1197-1212.

[27] Nooruddin, I. (2002), 'Modeling Selection Bias in Studies of Sanctions Efficacy', International Interactions, 28 (1), 59-75.

[28] Rouhani, Hassan (2013), 'Why Iran seeks constructive engagement', Washington Post, September $10,2013$.

[29] Wintrobe, R. (2006), 'Extremism, Suicide Terror, and Authoritarianism', Public Choice, 128, 169195. 


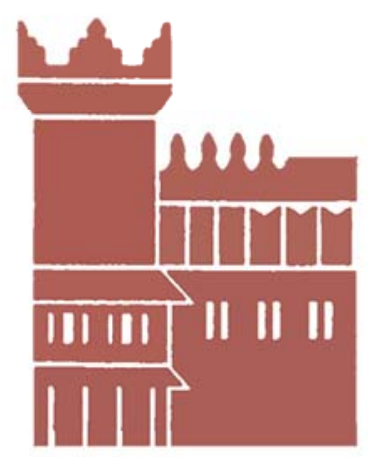

Alma Mater Studiorum - Università di Bologna DEPARTMENT OF ECONOMICS

Strada Maggiore 45

40125 Bologna - Italy

Tel. +39051 2092604

Fax +390512092664

http://www.dse.unibo.it 